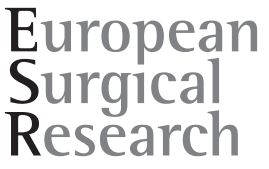

\title{
Uniformity of Chronic Pain Assessment after Inguinal Hernia Repair: A Critical Review of the Literature
}

\author{
Marijke Molegraafa Johan Lange ${ }^{b}$ Arthur Wijsmuller ${ }^{c}$ \\ ${ }^{a}$ Department of Surgery, Erasmus University Medical Center, Rotterdam, and \\ ${ }^{b}$ Department of Surgery, University Medical Center Groningen, Groningen, The Netherlands; \\ 'Research Institute against Digestive Cancer (IRCAD), Department of General, \\ Digestive and Endocrine Surgery, University Hospital of Strasbourg, Strasbourg, France
}

\section{Key Words}

Hernia · Chronic pain · Quality of life · Uniform assessment · Outcome definition

\begin{abstract}
Background: Chronic postoperative inguinal pain (CPIP) is the most common long-term complication of inguinal hernia repair. As such procedures are routinely performed, CPIP can be considered a significant burden to global health care. Therefore, adequate preventative measures relevant to surgical practice are investigated. However, as no gold standard research approach is currently available, study and outcome measures differ between studies. The current review aims to provide a qualitative analysis of the literature to seek out if outcomes of CPIP are valid and comparable, facilitating recommendations on the best approach to preventing CPIP. Methods: A systematic review of recent studies investigating CPIP was performed, comprising studies published in 2007-2015. Study designs were analyzed regarding the CPIP definitions applied, the use of validated instruments, the availability of a baseline score, and the existence of a minimal follow-up of 12 months. Results: Eighty eligible studies were included. In 48 studies, 22 different definitions of CPIP were identified, of which the definition provided by the International Association for the Study of Pain was applied most often. Of the studies included, 53 (66\%) used 33 different validated instruments to quantify CPIP. There were 32 studies (40\%) that assessed both pain intensity (PI) and quality of life (QOL) with validated tools, $41 \%$ and $4 \%$ had a validated assessment of only PI or $\mathrm{QOL}$, respectively, and $15 \%$ lacked a validated assessment. The visual analog scale and the Short Form 36 (SF36) were most commonly used for measuring PI (73\%) and QOL (19\%). As-
\end{abstract}


sessment of CPIP was unclear in 15\% of the studies included. A baseline score was assessed in $45 \%$ of the studies, and $75 \%$ had a follow-up of at least 12 months. Conclusion: The current literature addressing CPIP after inguinal hernia repair has a variable degree of quality and lacks uniformity in outcome measures. Proper comparison of the study results to provide conclusive recommendations for preventive measures against CPIP therefore remains difficult. These findings reaffirm the need for a uniform and validated assessment with uniform reporting of outcomes to improve the burden that CPIP poses to a significant surgical patient population.

\section{Introduction}

Chronic postoperative inguinal pain (CPIP) is the most common complication following inguinal hernia repair, occurring in roughly $20 \%$ of patients $[1,2]$. As inguinal hernia repair is a routinely performed surgical procedure, the frequent occurrence of CPIP constitutes a significant burden on surgical care [3]. As a result, CPIP has provided a strong incentive to optimize preventive and therapeutic strategies, yielding a large number of investigative studies over the recent decades. However, subsequent reviews have been faced with significant heterogeneity in study methods and outcomes. The heterogeneity of the available studies is largely attributable to the varying application of definitions of CPIP, the different timing of postoperative assessment utilizing different measurements, and the lack of standardized reporting of outcome results. Such heterogeneous data may be considered insufficient as a basis for consensus, which needs uniform and validated study designs to ensure the adequacy of the scientific evidence for clinical decision-making [4]. As a solution, the Initiative on Methods, Measurement, and Pain Assessment in Clinical Trials (IMMPACT) working group [5] and the International Association for the Study of Pain (IASP) [6] recommended core outcome domains to be considered in the development of studies investigating CPIP. These core domains comprise pain intensity (PI), consequences of chronic pain on physical and emotional functioning, and participants' rating of overall improvement. In addition, these core outcomes should be measured prospectively over a minimal follow-up of 1 year using 2 or more standardized assessment tools.

Furthermore, the National Institute for Health and Clinical Excellence (NICE) has emphasized the importance of utilizing prospective study designs to address these core outcome domains, in order to standardize definitions and assessment methods of pain [7]. The aim of the current review is to investigate whether the recommendations made in 2005 by the IMMPACT, IASP, and NICE have led to improved uniformity and quality in the design of studies focusing on CPIP to a degree that allows the formation of conclusive recommendations to reduce the onset of CPIP.

\section{Methods}

Search Strategy

The literature search was performed using several databases, which were MEDLINE in PubMed, Embase, and the Cochrane Library. The following MeSH terms were combined: 'hernia, inguinal', 'chronic pain', 'herniorrhaphy', and 'Lichtenstein'. To ensure that the search yielded a complete overview of the current literature, the MeSH terms were used in conjunction with free-text word combinations, as this search strategy would also cover papers without appropriate MeSH terms and papers not yet fitted with MeSH terms. The search was restricted to articles published in the English language from 2007 to 2015 to obtain the most recent studies that were relevant to the aim of this review. 


\begin{tabular}{l|l}
\hline Eur Surg Res 2017;58:1-19 \\
\hline DOI: 10.1159/000448706 & $\begin{array}{l}\text { C 2016 The Author(s). Published by S. Karger AG, Basel } \\
\text { www.karger.com/esr }\end{array}$ \\
\hline
\end{tabular}

Molegraaf et al.: Uniformity of Chronic Pain Assessment after Inguinal Hernia Repair: A Critical Review of the Literature

\section{Inclusion Criteria}

Studies

Prospective studies and study protocols with the Lichtenstein method as the referring technique were included, irrespective of the application or method of randomization. Also, to suit the purpose of this review, studies were included regardless of their sample size, publication status, and whether it concerned single- or multi-center studies.

Patients

As this study focused on the adult patient population, all patients aged 18 years and above were included. All types of hernia (primary or recurrent, uni- or bilateral) that were investigated were included for both adult male and female populations to ensure the broad applicability of our results in a large and diverse patient population in clinical practice.

Interventions

Correction of an inguinal hernia occurred, irrespective of the surgical technique.

Outcomes

CPIP was among the primary or secondary outcomes.

\section{Review Process}

The review process was performed in two steps. First, all abstracts were assessed according to the eligibility criteria, consulting the full-text papers in case of doubt about whether the study met these criteria. Next, all full-text papers of the selected abstracts were read and analyzed in full to make a final decision about their inclusion.

\section{Outcomes of Interest}

According to the recommendations of the IMMPACT, IASP, and NICE, all included studies were scored for the presence of:

1 a formal definition of CPIP;

2 validated measurement of both PI and the effects of CPIP on daily functioning or quality of life (QOL);

3 a duration of follow-up of at least 12 months;

4 a baseline score: preoperative measurement of PI and QOL.

One point was assigned to a study for the availability of each of the abovementioned aspects, so that each study was assigned an overall methodological quality score ranging from 0 to 4 .

\section{Results}

Using the strategy described above, the search yielded 234 hits (see the PRISMA flowchart in fig. 1). After applying the search limitations, 109 articles remained eligible for inclusion. Following a critical review of the full texts of these articles, 29 articles were excluded for not meeting the inclusion criteria. The reasons for exclusion at this stage were a retrospective study design, the article being either a review or a comment, or CPIP not being among the primary or secondary outcomes. Also, studies reporting the long-term follow-up results of another included study were considered redundant and were therefore excluded.

Following the critical review, 80 studies fitted the eligibility criteria. Among these studies, 52 articles described RCTs and 38 studies had a comparative study design (table 1). Most studies investigated the Lichtenstein technique using different meshes $(n=10)$, fixation methods (ProGrip mesh: $n=13$; glue: $n=10)$, analgesics $(n=3)$, and methods of nerve handling $(n=5)$. Other studies compared the Lichtenstein technique with pre- or retroperitoneal mesh placement: total extraperitoneal repair $(n=12)$, Prolene Hernia System repair $(n=4)$, plug and patch $(n=4)$, Kugel $(n=2)$, transinguinal preperitoneal repair $(n=1)$, and transabdominal preperitoneal repair $(n=5)$. Seven studies compared Lichtenstein hernio- 


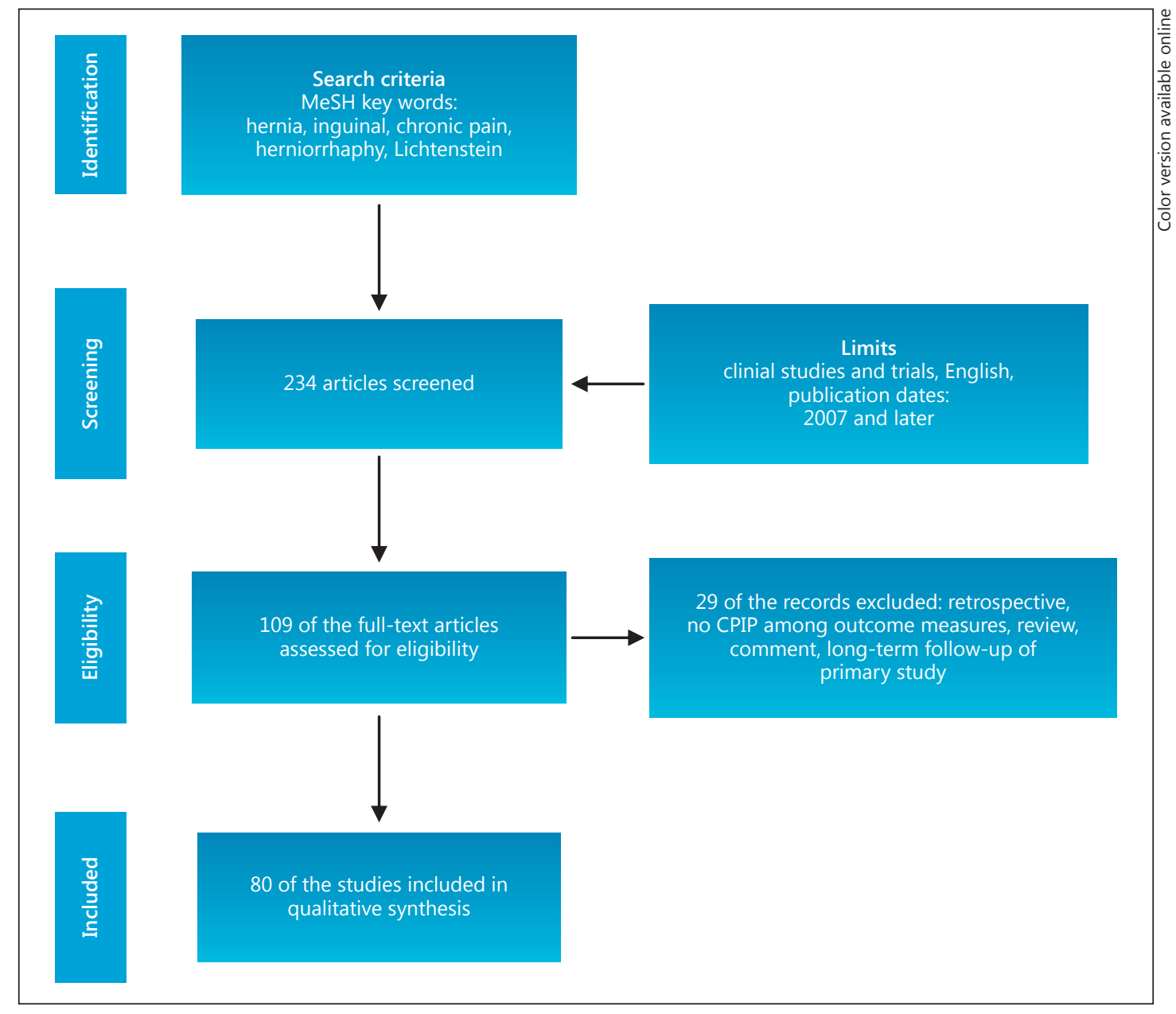

Fig. 1. PRISMA flowchart. Overview of the literature search.

plasty with non-mesh techniques: Moloney's darn repair $(n=2)$, Shouldice's repair $(n=1)$, the Desarda technique $(n=1)$, and suture repair $(n=2)$. In 55 studies, CPIP was the primary outcome measure; in the remaining studies, CPIP was among the secondary outcome measures.

\section{Definition of CPIP}

A definition of CPIP was lacking in 31 (39\%) of the studies (table 2) [8-38]. In the other 49 studies (61\%), a total of 22 different definitions of CPIP were identified. Almost half $(n=$ 23 ) of these studies applied the definition provided by the IASP, which is 'chronic pain is pain that persists beyond three months post-operatively' [39-62]. The remaining half $(n=26)$ used multiple definitions of CPIP, which can be categorized and summarized as follows. First, there was heterogeneity in the postoperative time period after which pain was classified as chronic. This 'chronic' time frame ranged between 1 and 36 months [63-67]. Second, some studies included the quantitative factor PI in their definition of CPIP, which was either expressed using descriptive terms [68-75], a visual analog scale (VAS) score, or a QOL score [31, 76-85]. 


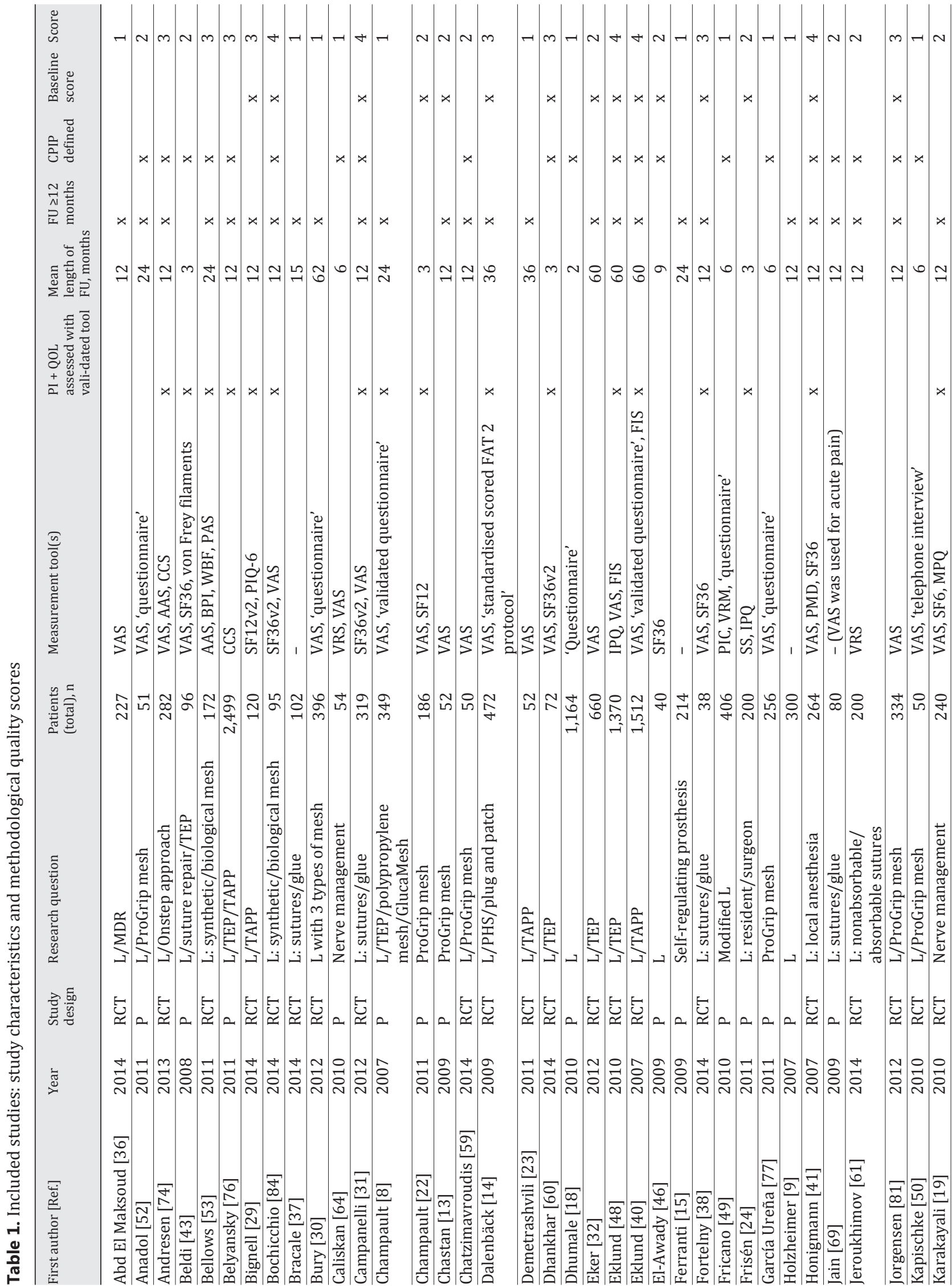


European
Surgical
Research

Eur Surg Res 2017:58:1-19

DOI: 10.1159/000448706

C 2016 The Author(s). Published by S. Karger AG, Base www.karger.com/esr

Molegraaf et al.: Uniformity of Chronic Pain Assessment after Inguinal Hernia Repair: A Critical Review of the Literature

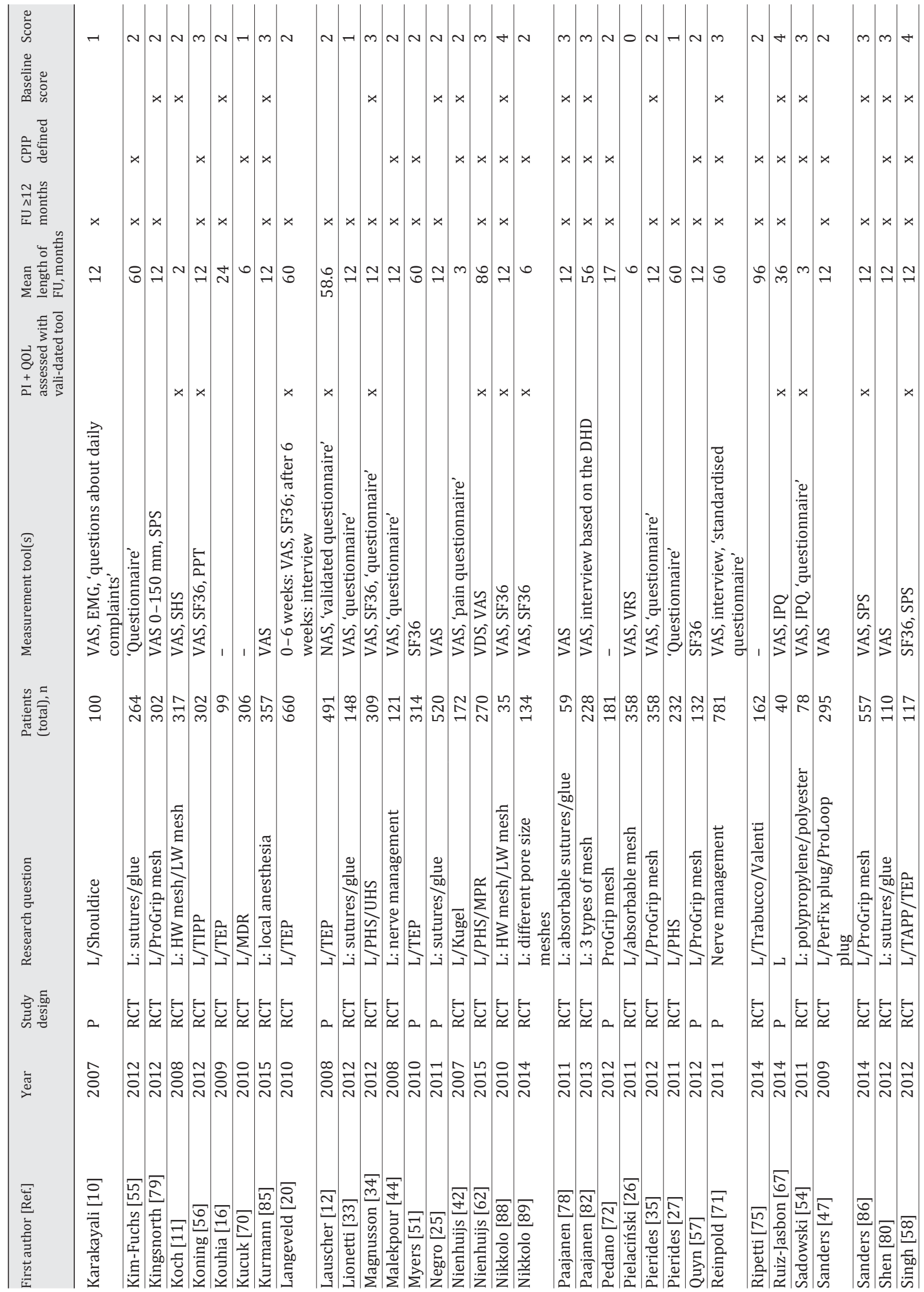




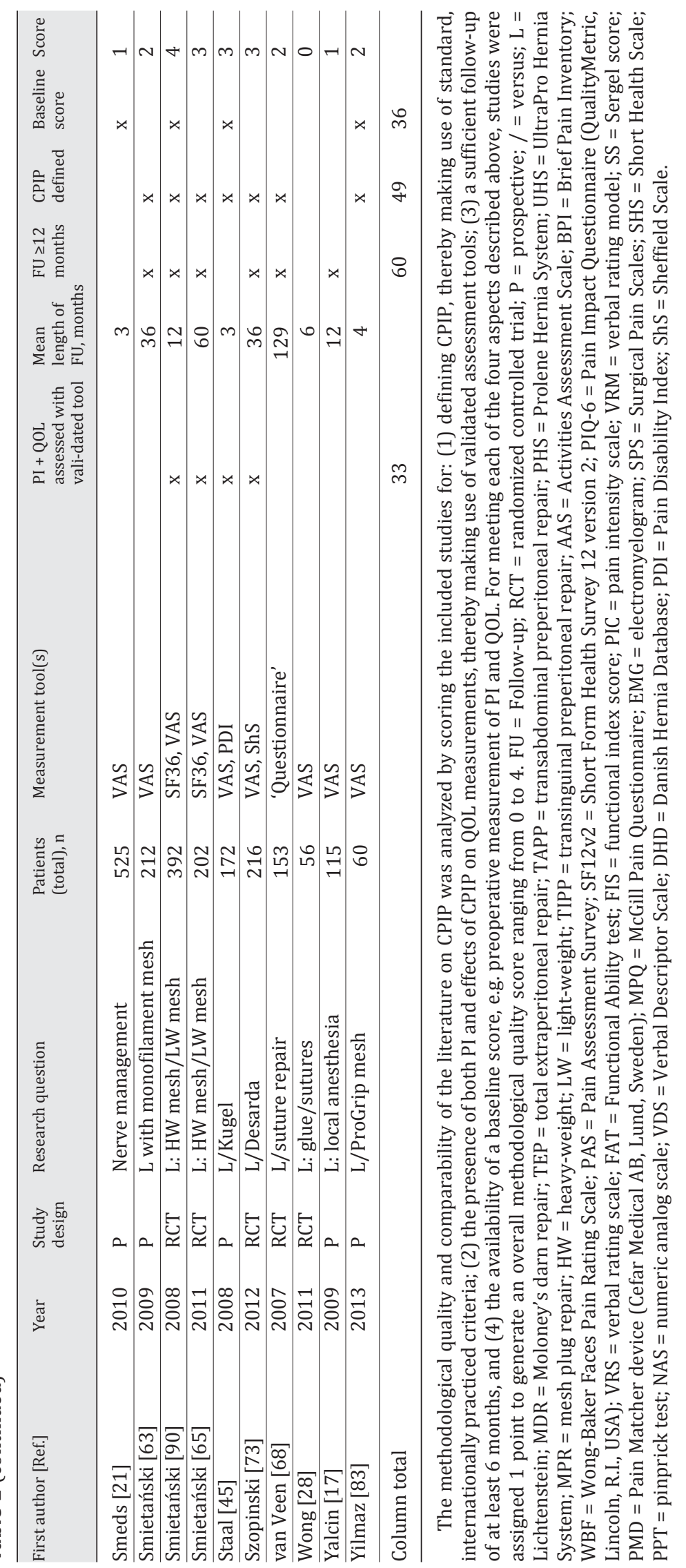


Table 2. Overview of the different definitions of CPIP used in the included studies ( $\mathrm{n}=49 ; 61 \%)$

\begin{tabular}{|c|c|}
\hline First author [Ref.] & Definition of CPIP \\
\hline $\begin{array}{l}\text { Anadol [52], Beldi [43], Bellows [53], Chatzimavroudis } \\
\text { [59], Dhankhar [60], Eklund [40,48], El-Awady [46], } \\
\text { Fricano [49], Honigmann [41], Jeroukhimov [61], } \\
\text { Kapischke [50], Kim-Fuchs [55], Koning [56], } \\
\text { Malekpour [44], Myers [51], Nienhuijs [42, 62], Quyn } \\
\text { [57], Sanders [47], Sadowski [54], Singh [58], Staal [45] } \\
(\mathrm{n}=23)\end{array}$ & IASP: any VAS lasting >3 months \\
\hline Andresen [74] & $\begin{array}{l}\text { Pain-related impairment of function at } 6 \text { months } \\
\text { defined as AAS }>8.3 \\
\text { Pain that impairs daily function at } 12 \text { months }\end{array}$ \\
\hline Jain [69], Ripetti [75] & $\begin{array}{l}\text { Proportion of patients with pain that impairs } \\
\text { daily function at } 12 \text { months }\end{array}$ \\
\hline Smietański $[63,65,90]$ & Pain lasting >12 months (Kehlet) \\
\hline Caliskan [64] & Pain lasting $>1$ month \\
\hline Ruiz-Jasbon [67] & Pain at 36 months \\
\hline Pedano [72] & Invalidating pain lasting $>3$ months \\
\hline Yilmaz [83] & VAS $>0$ at 4 months \\
\hline Campanelli [31], Jorgensen [81] & VAS $>30$ at 12 months \\
\hline Kurmann [85] & $\begin{array}{l}\text { VAS } \geq 30 \text { in any quality (at rest, lying, walking, } \\
\text { climbing stairs, and bending over) at } 3 \text { months }\end{array}$ \\
\hline García Ureña [77] & VAS $>3$ at 3 and 6 months \\
\hline Bochicchio [84] & Any VAS at 3 and 12 months \\
\hline Kingsnorth [79] & VAS $45 / 150$ lasting $>3$ months \\
\hline Shen $[80]$ & $\begin{array}{l}\text { Moderate or greater pain }(\mathrm{VAS}>4) \text { in the } \\
\text { inguinal area at } 3 \text { months }\end{array}$ \\
\hline Belyansky [76] & CCS $>1$ lasting $>3$ months \\
\hline Kucuk [70] & Pain lasting $>2$ months and requiring painkillers \\
\hline Nikkolo $[88,89]$ & Pain at rest at 6 months \\
\hline Paajanen [78] & VAS $>2$ lasting $>3$ months \\
\hline Paajanen [82] & VAS $>3$ at 12 months \\
\hline Reinpold [71] & Pain once a fortnight lasting $>6$ months \\
\hline Szopinski [73] & Moderate or strong pain lasting $>6$ months \\
\hline van Veen [68] & Pain interfering with daily activities \\
\hline
\end{tabular}

AAS = Activities Assessment Scale; CCS = Carolinas Comfort Scale

In addition to incorporating a definition of CPIP, 31 studies (39\%) provided a categorization of pain severity (table 3 ). In half of the studies, the categorization consisted of reporting the effect of CPIP on daily life using 9 different validated or nonvalidated criteria (table 3) [33, $40,48,52,58,61,62,68,73,79,86]$. The remaining studies used a categorization of pain severity based on VAS or numerical analog scale measurements $[8,10,19,22,23,50,56,71$, 73, 81, 87-89]. The subsequent categorization of PI was highly heterogeneous (fig. 2). Some studies incorporated a minimal PI score to distinguish between clinically relevant or minor CPIP $[14,31,71,74,76]$.

\section{Assessment of CPIP}

Tool(s)

Fifty-three studies (66\%) used only validated instruments for the assessment of CPIP. However, among these studies, 33 different validated instruments were identified (tables 4-6) $[11,13,14,17,19,21,26,28,29,32,36,38,41,43,45,47,48,51,53,56-65,79,90]$. 
Molegraaf et al.: Uniformity of Chronic Pain Assessment after Inguinal Hernia Repair: A Critical Review of the Literature

Table 3. Overview of the different definitions and categories of pain severity

\begin{tabular}{|c|c|}
\hline First author [Ref.] & Categories of CPIP \\
\hline Anadol [52] & $\begin{array}{l}\text { 'Intolerable pain' = 'intractable' or 'hard to live with', and pain which } \\
\text { requires pain medication and/or medical consultation }\end{array}$ \\
\hline Szopinski [73] & $\begin{array}{l}\text { Sheffield scale: } \\
0=\text { no pain } \\
1 \text { = no pain at rest but it appears during movement } \\
2 \text { = temporary pain at rest and moderate during movement } \\
3 \text { = constant pain at rest and severe during movements }\end{array}$ \\
\hline $\begin{array}{l}\text { Eklund }[40,48] \\
\text { Smietański }[90]\end{array}$ & $\begin{array}{l}\text { Mild = occasional discomfort or pain not interfering with daily activities } \\
\text { Moderate = discomfort or pain occasionally interfering with daily activities } \\
\text { Severe = discomfort or pain interfering with daily activities }\end{array}$ \\
\hline van Veen [68] & Pain and discomfort whether or not it interferes with daily activity \\
\hline Lionetti [33] & $\begin{array}{l}\text { Cunningham's criteria: } \\
\text { Mild = occasional pain or discomfort that did not limit activity, with a } \\
\text { return to pre-hernia lifestyle } \\
\text { Moderate = pain preventing return to normal preoperative activities } \\
\text { (inability to continue any sports or to lift objects without pain) } \\
\text { Severe = pain constantly or intermittently present, but so severe as to } \\
\text { impair normal activities such as walking }\end{array}$ \\
\hline Jeroukhimov [61] & $\begin{array}{l}\text { Mild = occasional pain or discomfort that did not limit daily activity and did } \\
\text { not require pain medicine } \\
\text { Moderate = pain that interfered with a return to normal everyday activity } \\
\text { with rare analgesic requirement } \\
\text { Severe = pain that incapacitated the patient, occurred at frequent intervals, } \\
\text { or interfered with everyday activities with a frequent need for painkillers }\end{array}$ \\
\hline Nienhuijs [62] & $\begin{array}{l}\text { Pain was graded into non/mild/moderate and severe using a Verbal } \\
\text { Descriptor Scale for different aspects of life }\end{array}$ \\
\hline $\begin{array}{l}\text { Kingsnorth [79], } \\
\text { Sanders [47], Singh [58] }\end{array}$ & $\begin{array}{l}\text { Surgical Pain Scale: measures pain while at rest, during normal activities, } \\
\text { and during work or exercise, and pain unpleasantness }\end{array}$ \\
\hline Belyansky [76] & Relevant pain $=\mathrm{CCS}>1$ \\
\hline $\begin{array}{l}\text { Ruiz-Jasbon [67], } \\
\text { Sadowski [54] }\end{array}$ & $\begin{array}{l}\text { Pain or no pain in different situations according to the IPQ: if there was } \\
\text { pain, a score on a VAS was asked }\end{array}$ \\
\hline Andresen [74] & Moderate-to-severe pain = VAS $4-10$ \\
\hline Campanelli [31] & Relevant pain = VAS >30 \\
\hline Dalenbäck [14] & Severe $=$ VAS $>70$ \\
\hline $\begin{array}{l}\text { Champault [8], } \\
\text { Demetrashvili [23] }\end{array}$ & Mild $=$ VAS $<30 ;$ moderate $=$ VAS $<50 ;$ severe or debilitating $=$ VAS $>50$ \\
\hline $\begin{array}{l}\text { Champault [22], } \\
\text { Jorgensen [81] }\end{array}$ & Mild $=$ VAS 1-30; moderate $=$ VAS 31-60; severe $=$ VAS $>60$ \\
\hline Nikkolo $[88,89]$ & Mild = VAS 1-10; moderate $=$ VAS $11-50 ;$ severe $=$ VAS $>50$ \\
\hline Reinpold [71] & $\begin{array}{l}\text { Not relevant } \mathrm{CP} \text { : mild } \mathrm{CP}=\mathrm{VAS} 1-3 \\
\text { Relevant } \mathrm{CP} \text { : } \text { moderate } \mathrm{CP}=\mathrm{VAS} 4-6 \text {; strong } \mathrm{CP}=\text { VAS } 7-9 \text {; } \\
\text { very strong } \mathrm{CP}=\text { VAS } 10\end{array}$ \\
\hline $\begin{array}{l}\text { Karakayali }[10,19] \text {, } \\
\text { Koning [56] }\end{array}$ & Mild $=$ VAS $1-30 ;$ moderate $=$ VAS $40-70 ;$ severe $=$ VAS $>70$ \\
\hline
\end{tabular}


Table 3 (continued)

\begin{tabular}{ll}
\hline First author [Ref.] & Categories of CPIP \\
\hline Szopinski [73] & Moderate = VAS $30-54$; strong $=$ VAS $>54$ \\
\hline Kapischke [50] & Low to medium = VAS $0-40 ;$ medium to strong $=$ VAS $>40$ \\
\hline Lauscher [12] & Weak = NAS $1-3$; moderate $/$ severe $=$ NAS $>3$ \\
\hline
\end{tabular}

$\mathrm{CP}=$ Chronic pain; NAS $=$ numeric analog scale .

Table 4. Number of studies that uses validated or nonvalidated assessment tools to measure CPIP

\begin{tabular}{lc}
\hline Type of assessment tool used & Studies, $\mathrm{n}(\%)$ \\
\hline No information given & $8(10)$ \\
Nonvalidated questionnaire: separate questions, written or by interview & $19(24)$ \\
$\quad$ As a single measurement tool & 4 \\
$\quad$ In combination with a validated PI score & 12 \\
$\quad$ In combination with a validated PI and QOL score & 3 \\
Only validated questionnaire(s) or PI scale (number of different tools: $\mathrm{n}=30)$ & $53(66)$ \\
\hline
\end{tabular}

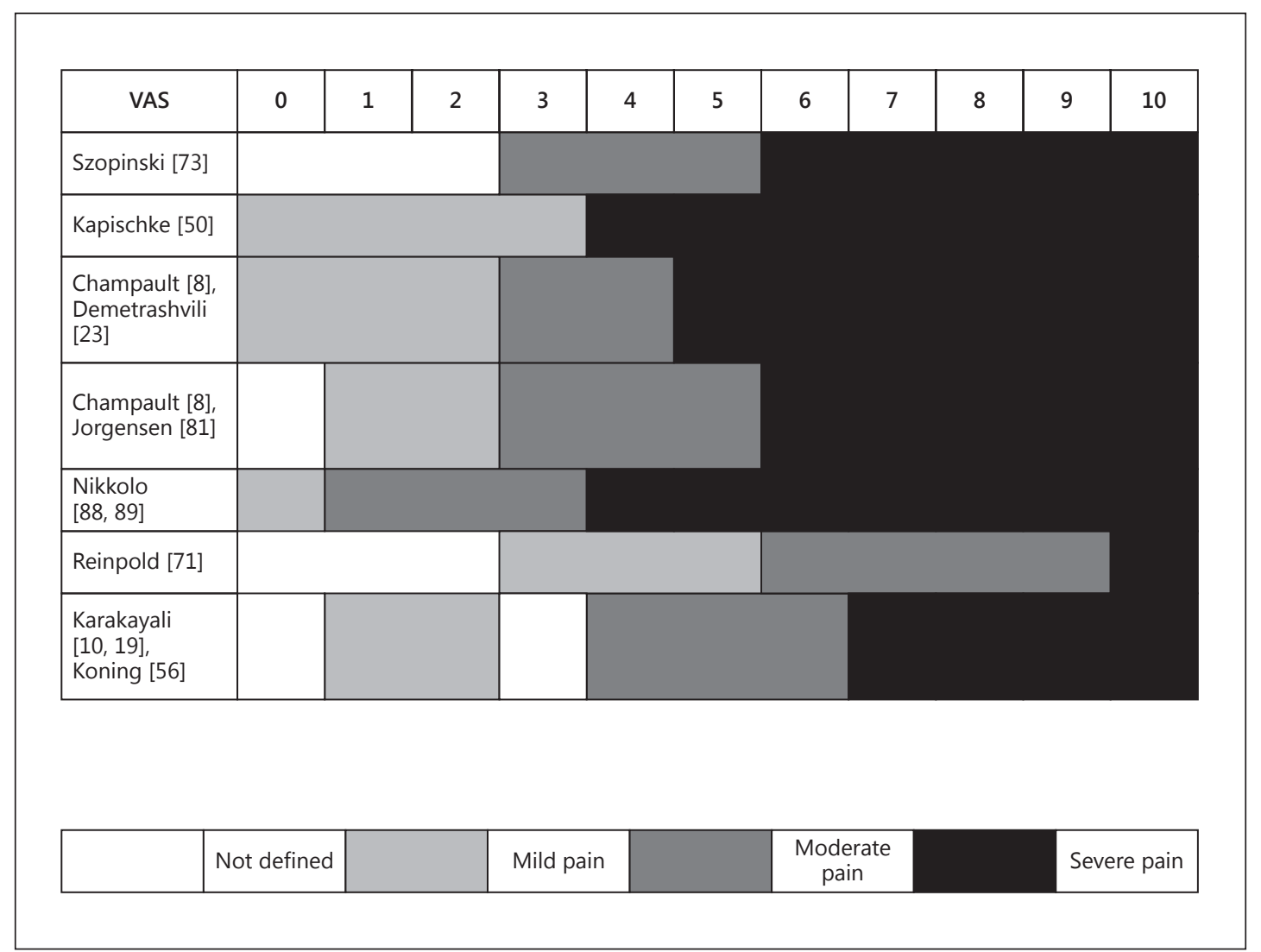

Fig. 2. Categories of CPIP based on VAS scores. Thirty-one studies (39\%) provided definitions of the severity of CPIP (table 3). Fifteen studies defined pain severity in terms of PI according to the score on a VAS or numerical analog scale. The categories of PI based on VAS scores were heterogeneous and thus not comparable. 
Molegraaf et al.: Uniformity of Chronic Pain Assessment after Inguinal Hernia Repair: A Critical Review of the Literature

Table 5. Tools used to measure CPIP

\begin{tabular}{|c|c|c|}
\hline Abbreviation & Full name & $\begin{array}{l}\text { Number of } \\
\text { studies it is used in }\end{array}$ \\
\hline AAS & Activities Assessment Scale & 3 \\
\hline BPI & Brief Pain Inventory & 1 \\
\hline CCS & Carolinas Comfort Score & 2 \\
\hline DHD & Danish Hernia Database questionnaire & 1 \\
\hline FAT & Functional Ability test & 1 \\
\hline FIS & Functional Index Score & 2 \\
\hline IPQ & Inguinal Pain Questionnaire & 4 \\
\hline MPQ & McGill Pain Questionnaire & 1 \\
\hline NAS & Numeric analog scale & 1 \\
\hline PAS & Pain Assessment Survey & 1 \\
\hline PDI & Pain Disability Index & 1 \\
\hline PIQ-6 & Pain Impact Questionnaire & \\
\hline PIC & Pain intensity scale & 1 \\
\hline PPT & Pinprick test & 1 \\
\hline PMD & Pain Matcher device & 2 \\
\hline SF12/SF12v2 & Short Form 12/Short Form 12 version 2 & 2 \\
\hline SF36/SF36v2 & Short Form 36/Short Form 36 version 2 & 16 \\
\hline SF-6D & Short Form - 6 Dimensions & 1 \\
\hline SHS & Short Health Scale & 2 \\
\hline SPS & Surgical Pain Scales & 3 \\
\hline ShS & Sheffield Scale & 1 \\
\hline SS & Sergel score & 1 \\
\hline VAS-100 mm & Visual analog scale $0-100 \mathrm{~mm}$ & 57 \\
\hline VAS-150 mm & Visual analog score $0-150 \mathrm{~mm}$ & 1 \\
\hline VDS & Verbal Descriptor Scale & 1 \\
\hline VRM & Verbal rating model & 1 \\
\hline VRS & Verbal rating scale $(0-100)$ & 3 \\
\hline VRS-4 & Verbal rating scale $(0-4)$ & 1 \\
\hline WBF & Wong-Baker Faces Pain Rating Scale & 1 \\
\hline \multirow[t]{2}{*}{$\mathrm{FF}$} & von Frey filaments & 1 \\
\hline & 'Validated questionnaire' & 3 \\
\hline
\end{tabular}

In 19 studies (24\%), nonvalidated instruments were used [10, 18, 20, 27, 30, 33-35, 40, $42,44,49,50,52,54,65,68,71,77,82]$. The majority of these studies described these instrument using nonspecific phrases such as 'a questionnaire was used' or 'patients were interviewed'. Of these studies, 15 utilized a nonvalidated instrument in conjunction with a VAS [10, 30, 33-35, 40, 42, 44, 50, 52, 71, 77, 82], verbal rating scale [49], inguinal pain questionnaire (IPQ) [54], or functional index score [40].

In 8 studies $(10 \%)$ there was no information provided about how the data were collected $[9,15,16,37,70,72,75]$.

Validated Assessment of both PI and QOL

Thirty-two studies (40\%) had a validated assessment of both PI and QOL [11, 14, 19, 20, $22,24,29,31,34,38,40,41,43,45,48,53,54,56,58,60,62,65,67,73,74,76,84,86-90]$; in $33(41 \%)$ and $3(4 \%)$ of the studies, respectively, there was only a validated assessment of PI $[8,10,13,17,21,23,25,26,28,30,33,35,36,42,44,47,49,50,52,59,61,63,69,71,77,78$, $80-83,85]$ or QOL $[46,51,57]$.

In 12 studies (15\%) there was a validated assessment of neither PI nor QOL $[9,15,16$, $18,27,37,55,68,70,72,75]$. 
Table 6. Tools used to assess QOL and/or PI

\begin{tabular}{lll}
\hline QOL or functional assessment & PI & QOL + PI \\
\hline Activities Assessment Scale & Numeric analog scale & CCS \\
Activity Restriction Questionnaire & Pain intensity scale & Brief Pain Inventory \\
Danish Hernia Database questionnaire & Pain Matcher device & McGill Pain Questionnaire \\
Functional Ability Test & Pinprick test & Short Health Scale \\
Functional Index Score & Surgical Pain Scales & IPQ \\
Pain Disability Index & Sheffield Scale & \\
SF12/SF12v2 & Sergel score & \\
SF36 & VAS 0-100 mm & \\
SF-6 & VAS 0-150 mm & \\
Pain Impact Questionnaire & Verbal rating model & \\
& Verbal rating scale & \\
& Verbal Descriptor Scale & \\
& Wong-Baker Faces Pain Rating Scale & \\
\hline
\end{tabular}

Table 7. Methodological quality score

\begin{tabular}{|c|c|c|c|c|c|c|}
\hline & \multicolumn{2}{|c|}{ Overall $(n=80)$} & \multicolumn{2}{|c|}{$2007-2010(n=33)$} & \multicolumn{2}{|c|}{$2011-2015(n=47)$} \\
\hline & $\mathrm{n}$ & $\%$ & $\mathrm{n}$ & $\%$ & $\mathrm{n}$ & $\%$ \\
\hline \multirow[t]{2}{*}{4 points } & 9 & 11 & 5 & 15 & 4 & 9 \\
\hline & & 100 & & 56 & & 44 \\
\hline \multirow[t]{2}{*}{3 points } & 21 & 26 & 2 & 6 & 19 & 40 \\
\hline & & 100 & & 10 & & 90 \\
\hline \multirow[t]{2}{*}{2 points } & 30 & 38 & 15 & 45 & 15 & 32 \\
\hline & & 100 & & 50 & & 50 \\
\hline \multirow[t]{2}{*}{1 point } & 18 & 23 & 11 & 34 & 7 & 15 \\
\hline & & 100 & & 61 & & 39 \\
\hline \multirow[t]{2}{*}{0 points } & 2 & 2 & 0 & 0 & 2 & 4 \\
\hline & & 100 & & 0 & & 100 \\
\hline
\end{tabular}

The methodological quality and comparability of the literature on CPIP was analyzed by scoring the included studies for: (1) CPIP being defined, thereby making use of standard, internationally practiced criteria; (2) both PI and effects of CPIP on QOL are measured, thereby making use of validated assessment tools; (3) a sufficient follow-up of at least 6 months, and (4) availability of a baseline score, e.g. preoperative measurement of PI and QOL. One point each was assigned for the availability of one the abovementioned aspects, and each study was assigned an overall methodological quality score ranging from 0 to $4 . \chi^{2}$ test: $\mathrm{p}=0.005$.

The majority of the studies investigating PI used VAS measurements, while QOL was most often examined using the Short Form 36 (SF36) questionnaire (tables 1,6). Of the instruments that incorporate the assessment of both PI and QOL, the IPQ was used most often.

Duration of Follow-Up of at Least 12 Months

The duration of follow-up ranged from 6 weeks to 96 months. Sixty studies (75\%) had a follow-up of 12 months or longer, with a median of 12 months (table 1).

Availability of a Baseline Score: Preoperative Measurement of PI and Its Consequences for Daily Functioning/QOL

A baseline score was assessed by $45 \%$ (36/80) of the studies included (table 1$)$. 
Molegraaf et al.: Uniformity of Chronic Pain Assessment after Inguinal Hernia Repair: A Critical Review of the Literature

\section{Methodological Quality Score}

The full amount of 4 points was scored by $11 \%$ of the studies; $26 \%$ scored 3 points, $38 \%$ scored 2 points, $23 \%$ scored 1 point, and $2 \%$ scored 0 points (table 7 ). When comparing the periods of 2007-2010 and 2011 until today there is a significant improvement in methodological quality scores $(\mathrm{p}=0.005)$. The best score was given for the criterion of having a minimum of 12 months of follow-up and the second best for the availability of a definition of CPIP; on the third place was the performance of a baseline measurement, and last a validated assessment of both PI and QOL.

\section{Discussion}

The results from this review demonstrate that the current scientific literature investigating the management of CPIP after inguinal hernia repair is flawed due to a lack of adherence to standards in study methodology and tools as well as the nonexistence of commonly accepted definitions of the primary outcome. We found that although the majority of the studies provided similar definitions of CPIP, the variable interpretation of these definitions does not allow for adequate comparisons, opposes uniformity, and therefore obstructs evidence-based clinical decision-making. Similarly, despite the fact that the majority of the included studies did use a validated assessment tool to quantify CPIP, we found that a total of 33 different tools were used among these studies. Measurements of PI and QOL, which are both included in the recommendations of the IMMPACT and IASP, were performed using nonvalidated tools in a majority of the studies. Furthermore, the greater number of these studies provided no preoperative baseline measurements of CPIP, which clouds the interpretation of their outcome findings.

Despite the efforts put in by the scientific community, it appears that the current scientific literature about CPIP is heterogeneous to a degree that limits meta-analyses. Interestingly, the clinical relevance of this conclusion is not limited to the current state of scientific literature. Similar conclusions were drawn by Kehlet et al. [4], who stated that no proper recommendations for preventing or treating CPIP could be made based on the sparse scientific evidence available over a decade ago. Based on their findings, they issued a call for uniformity and provided recommendations for an optimal study design as a solution for the heterogeneity. A more recent study published in 2007 by van Hanswijck de Jonge et al. [91] concluded that measurements of pain and discomfort scores remained highly heterogeneous as studies evaluated CPIP by different types of instruments of varying quality and accuracy.

Most of the studies included reported CPIP as the primary outcome. At a fundamental scientific level, the primary outcome of a study is the outcome parameter to be measured and compared, either to the control group in a comparative study or to results from the literature in noncomparative studies. Such a comparison to the literature requires the unambiguous definition of the primary endpoint in order to provide conclusions of scientific and clinical value. To further enhance the comparability of scientific literature, it is of great importance to comply with standardized international definitions and to adhere to accepted categorizations of outcome measures. In the case of the current CPIP literature, we found that $39 \%$ of the studies lacked a definition of the primary outcome. When a definition was provided, it was often a nonstandardized one, as we were able to identity 22 different CPIP definitions across the remaining 49 studies (table 2). The IASP definition of chronic pain was most frequently used, which states that 'chronic pain is any pain that persists beyond the normal tissue healing time usually taken to be 3 months' [39]. The other, nonstandardized definitions diverged with respect to duration, intensity, and severity. It appears that expert opinions differ regarding the cutoff points between acute and chronic pain. This might be expected, considering that 
Molegraaf et al.: Uniformity of Chronic Pain Assessment after Inguinal Hernia Repair: A Critical Review of the Literature

the IASP also uses different definitions of chronic pain and persistent postsurgical pain, which is defined as 'pain that develops after a surgical intervention and lasts at least two months excluding other causes for the pain' [6]. Aasvang and Kehlet [92] argued that given the possibility of an ongoing inflammatory reaction to a prosthetic mesh, CPIP should be measured at least 6 months postoperatively. Others used a minimum duration of 12 months, based on an earlier article of Kehlet et al. [4].

The definition of CPIP provided by the IASP is based solely on a time factor, as it regards discomfort to be any pain with a VAS above 0 . Alternative definitions incorporated a PI factor in their definition of CPIP. For example, such definitions state that a patient needs to express at least a VAS of 2 or 3 on a scale of 10 to be considered in pain. Others added descriptive terms of pain severity in their CPIP definition (table 2), such as discomfort or pain happening once a fortnight, requiring painkillers, or interfering with daily activities. These different and seemingly arbitrary thresholds of severity and duration in the definitions of chronic pain influence incidence and prevalence rates when incorporated into epidemiological studies and hinder comparisons between studies. In a recently published international expert consensus article, CPIP is defined as 'chronic inguinal post-operative pain that still exists and affects daily life six months post-operatively' [93]. However, the HerniaSurg Group, working on the World Guidelines for Groin Hernia Management, is now proposing to modify the IASP definition in order to include only chronic pain that is present from 3 months after surgery and which lasts beyond 6 months after surgery.

To generate high-quality evidence for the best preventive and treatment strategies for CPIP, it is imperative to use validated scales. To further enhance the comparability of scientific studies, these scales should ideally be standardized and clearly described in a paper [94]. Since 33 different instruments could be identified among the included studies, it seems that consensus about the optimal instrument for the assessment of CPIP is still lacking.

Several pain assessment tools have been developed to measure different aspects of pain. PI is mostly measured using verbal rating scales, numerical rating scales, and VAS [95]. In this review, we found that the VAS was predominantly used (in 73\% of the studies). However, these PI scales only provide a global estimation of a patient's experience of pain, without considering all the relevant aspects and consequences of chronic pain. To elaborate, chronic pain has a major impact on physical, emotional, and cognitive function. Furthermore, chronic pain can negatively affect patients' social life and their ability to work and secure an income, which also has economic implications that extend beyond health care [96]. The importance of identifying the repercussions of chronic pain as perceived by a patient was demonstrated by Fredheim et al. [97]. They found that patients with non-cancer-related chronic pain reported a QOL that was lower than that of terminal cancer patients. The IMMPACT group [5] and Kehlet et al. [4] therefore emphasized that in order to perform a meaningful assessment of chronic pain, it is required that quantitative measurement tools are utilized in conjunction with multidimensional qualitative tools such as health-related QOL instruments to adequately assess the impact of chronic pain. The Medical Outcome Survey SF36 (MOS SF-36 or SF36) is generally considered to be the gold standard in QOL measurement. The advantage of the generic SF36 is its broad implementation as it is well known by regulatory bodies and physicians. In addition, the SF36 is suitable for comparing changes in QOL between different diseases and treatments. However, some authors including Heniford et al. [98] argue that a disease-specific QOL measure is preferable to assess the impact of CPIP on QOL and patient satisfaction. In this review, 4 hernia-specific QOL measures were identified among 8 studies: the Carolinas Comfort Scale (CCS) [76], the IPQ [48], the Activities Assessment Scale [53], and a questionnaire based on the Danish Hernia Database [99]. Some studies used rating scales such as the VAS to measure QOL [62]. There are also questionnaires available that incorporate the assessment of PI (sensory dimension) and the degree of interference of chronic 
Molegraaf et al:: Uniformity of Chronic Pain Assessment after Inguinal Hernia Repair: A Critical Review of the Literature

pain with aspects of daily life (reactive dimension). Examples of such questionnaires are the general McGill Pain Questionnaire, the Short Health Scale, the Brief Pain Inventory [100], and the hernia-specific CCS and IPQ. Beside questionnaires, objective methods such as painevoked responses and quantitative sensory testing are gaining popularity but are not yet utilized on a regular basis. Deciding upon the appropriate questionnaire to use will likely remain challenging as long as consensus is lacking.

The majority of the studies reviewed lacked a baseline measurement of PI and QOL. This is unfortunate, as baseline measurements are necessary for a meaningful interpretation of postoperative results. Furthermore, preoperative pain is a known risk factor for developing CPIP and therefore holds clinical relevance that might be undermined when it is not incorporated into studies investigating CPIP [101].

To reiterate, the literature concerning the treatment and prevention of CPIP is highly heterogeneous and inconsistent. Since a consensus measure is the only way to bring about more standardized and comparable results, the CPIP literature will benefit from a common standard. This common standard should include one clear definition of the outcome measure CPIP, incorporating pain duration, PI, and the effects of chronic pain on daily activities. Also, a common study methodology is needed that uses well-defined standard outcome parameters which are evaluated with validated instruments and over a sufficient period of followup. Whether certain types of measurement tools should be recommended to further improve the uniformity among studies is open for discussion, for example by the HerniaSurge Group, who are currently designing a global guideline for the management of groin hernia. We recommend an easy-to-use, hernia-specific score incorporating assessments of both PI and QOL, such as the IPQ and CCS. Finally, baseline measurement should become common practice, and follow-ups should be done on standardized time points.

However, without an ambitious implementation plan designed to reach targeted groups, the impact of a common standard could be disappointing. Global recognition and awareness are essential and may be achieved via the worldwide hernia societies.

\section{Acknowledgments}

Thanks to Dr. S.F.A. Said for his critical review of the manuscript.

\section{Disclosure Statement}

There are no conflicts of interests and no funding sources to declare.

\section{References}

1 Nienhuijs S, Staal E, Strobbe L, Rosman C, Groenewoud H, Bleichrodt R: Chronic pain after mesh repair of inguinal hernia: a systematic review. Am J Surg 2007;194:394-400.

2 Jenkins JT, O’Dwyer PJ: Inguinal hernias. BMJ 2008;336:269-272.

3 Poobalan AS, Bruce J, Smith WC, King PM, Krukowski ZH, Chambers WA: A review of chronic pain after inguinal herniorrhaphy. Clin J Pain 2003;19:48-54.

4 Kehlet H, Bay-Nielsen M, Kingsnorth A: Chronic postherniorrhaphy pain - a call for uniform assessment. Hernia 2002;6:178-181.

5 Dworkin RH, Turk DC, Farrar JT, Haythornthwaite JA, Jensen MP, Katz NP, et al: Core outcome measures for chronic pain clinical trials: IMMPACT recommendations. Pain 2005;113:9-19.

6 Yang Y, Chengyuan W: Guidelines on the basic outcome data from International Association for the Study of Pain. Clin J Pain 2007;23:549.

7 McCormick DP, Baldwin CD, Klecan-Aker JS, Swank PR, Johnson DL: Association of early bilateral middle ear effusion with language at age 5 years. Ambul Pediatr 2001;1:87-90. 
8 Champault G, Bernard C, Rizk N, Polliand C: Inguinal hernia repair: the choice of prosthesis outweighs that of technique. Hernia 2007;11:125-128.

9 Holzheimer RG: Low recurrence rate in hernia repair - results in 300 patients with open mesh repair of primary inguinal hernia. Eur J Med Res 2007;12:1-5.

10 Karakayali F, Karatas M, Ozcelik U, Ekici Y, Basaran O, Moray G, et al: Influence of synthetic mesh on ilioinguinal nerve motor conduction and chronic groin pain after inguinal herniorrhaphy: a prospective randomized clinical study. Int Surg 2007;92:344-350.

11 Koch A, Bringman S, Myrelid P, Smeds S, Kald A: Randomized clinical trial of groin hernia repair with titaniumcoated lightweight mesh compared with standard polypropylene mesh. Br J Surg 2008;95:1226-1231.

12 Lauscher JC, Yafaei K, Buhr HJ, Ritz JP: Total extraperitoneal hernioplasty: does the long-term clinical course depend on the type of mesh? J Laparoendosc Adv Surg Tech A 2008;18:803-808.

13 Chastan P: Tension-free open hernia repair using an innovative self-gripping semi-resorbable mesh. Hernia 2009;13:137-142.

14 Dalenbäck J, Andersson C, Anesten B, Björck S, Eklund S, Magnusson O, et al: Prolene Hernia System, Lichtenstein mesh and plug-and-patch for primary inguinal hernia repair: 3-year outcome of a prospective randomised controlled trial. The BOOP study: bi-layer and connector, on-lay, and on-lay with plug for inguinal hernia repair. Hernia 2009;13:121-129; discussion 231.

15 Ferranti F, Marzano M, Quintiliani A: Use of a dynamic self-regulating prosthesis (P.A.D.) in inguinal hernia repair: our first experience in 214 patients. Chir Ital 2009;61:179-185.

16 Kouhia ST, Huttunen R, Silvasti SO, Heiskanen JT, Ahtola H, Uotila-Nieminen M, et al: Lichtenstein hernioplasty versus totally extraperitoneal laparoscopic hernioplasty in treatment of recurrent inguinal hernia - a prospective randomized trial. Ann Surg 2009;249:384-387.

17 Yalcin S, Ergul E: A single-surgeon, single-institute experience of 115 Lichtenstein hernia repairs under local anesthesia. Bratisl Lek Listy 2009;110:43-44.

18 Dhumale R, Tisdale J, Barwell N: Over a thousand ambulatory hernia repairs in a primary care setting. Ann R Coll Surg Engl 2010;92:127-130.

19 Karakayali F, Oksuz E, Turk E, Pekmez M, Karabulut Z, Yilmaz T, et al: Effectiveness of multiple neurectomies to prevent chronic groin pain after tension-free hernia repair. Int Surg 2010;95:40-48.

20 Langeveld HR, van't Riet M, Weidema WF, Stassen LP, Steyerberg EW, Lange J, et al: Total extraperitoneal inguinal hernia repair compared with Lichtenstein (the LEVEL-Trial): a randomized controlled trial. Ann Surg 2010;251:819-824.

21 Smeds S, Löfström L, Eriksson 0: Influence of nerve identification and the resection of nerves 'at risk' on postoperative pain in open inguinal hernia repair. Hernia 2010;14:265-270.

22 Champault G, Torcivia A, Paolino L, Chaddad W, Lacaine F, Barrat C: A self-adhering mesh for inguinal hernia repair: preliminary results of a prospective, multicenter study. Hernia 2011;15:635-641.

23 Demetrashvili Z, Qerqadze V, Kamkamidze G, Topchishvili G, Lagvilava L, Chartholani T, et al: Comparison of Lichtenstein and laparoscopic transabdominal preperitoneal repair of recurrent inguinal hernias. Int Surg 2011;96:233-238.

24 Frisén A, Starck J, Smeds S, Nyström PO, Kald A: Analysis of outcome of Lichtenstein groin hernia repair by surgeons-in-training versus a specialized surgeon. Hernia 2011;15:281-288.

25 Negro P, Basile F, Brescia A, Buonanno GM, Campanelli G, Canonico S, et al: Open tension-free Lichtenstein repair of inguinal hernia: use of fibrin glue versus sutures for mesh fixation. Hernia 2011;15:7-14.

26 Pielaciński K, Szczepanik AB, Misiak A, Wróblewski T: Randomized clinical trial comparing inguinal hernia repair with Lichtenstein technique using non-absorbable or partially absorbable mesh. Preliminary report. Wideochir Inne Tech Maloinwazyjne 2011;6:190-206.

27 Pierides G, Vironen J: A prospective randomized clinical trial comparing the Prolene Hernia System ${ }^{\circledR}$ and the Lichtenstein patch technique for inguinal hernia repair in long term: 2- and 5-year results. Am J Surg 2011; 202:188-193.

28 Wong JU, Leung TH, Huang CC, Huang CS: Comparing chronic pain between fibrin sealant and suture fixation for bilayer polypropylene mesh inguinal hernioplasty: a randomized clinical trial. Am J Surg 2011;202:34-38.

29 Bignell M, Partridge G, Mahon D, Rhodes M: Prospective randomized trial of laparoscopic (transabdominal preperitoneal-TAPP) versus open (mesh) repair for bilateral and recurrent inguinal hernia: incidence of chronic groin pain and impact on quality of life: results of 10 year follow-up. Hernia 2012;16:635-640.

30 Bury K, Smietański M; Polish Hernia Study Group: Five-year results of a randomized clinical trial comparing a polypropylene mesh with a poliglecaprone and polypropylene composite mesh for inguinal hernioplasty. Hernia 2012;16:549-553.

31 Campanelli G, Pascual MH, Hoeferlin A, Rosenberg J, Champault G, Kingsnorth A, et al: Randomized, controlled, blinded trial of Tisseel/Tissucol for mesh fixation in patients undergoing Lichtenstein technique for primary inguinal hernia repair: results of the TIMELI trial. Ann Surg 2012;255:650-657.

32 Eker HH, Langeveld HR, Klitsie PJ, van't Riet M, Stassen LP, Weidema WF, et al: Randomized clinical trial of total extraperitoneal inguinal hernioplasty vs Lichtenstein repair: a long-term follow-up study. Arch Surg 2012;147:256-260.

33 Lionetti R, Neola B, Dilillo S, Bruzzese D, Ferulano GP: Sutureless hernioplasty with light-weight mesh and fibrin glue versus Lichtenstein procedure: a comparison of outcomes focusing on chronic postoperative pain. Hernia 2012;16:127-131. 
34 Magnusson J, Nygren J, Thorell A: Lichtenstein, Prolene Hernia System, and UltraPro Hernia System for primary inguinal hernia repair: one-year outcome of a prospective randomized controlled trial. Hernia 2012; $16: 277-285$

35 Pierides G, Scheinin T, Remes V, Hermunen K, Vironen J: Randomized comparison of self-fixating and sutured mesh in open inguinal hernia repair. Br J Surg 2012;99:630-636.

36 Abd El Maksoud W, Abd El Salam M, Ahmed HH: Comparative study between Lichtenstein procedure and modified darn repair in treating primary inguinal hernia: a prospective randomized controlled trial. Hernia 2014;18:231-236.

37 Bracale U, Rovani M, Picardo A, Merola G, Pignata G, Sodo M, et al: Beneficial effects of fibrin glue (Quixil) versus Lichtenstein conventional technique in inguinal hernia repair: a randomized clinical trial. Hernia 2014; 18:185-192.

38 Fortelny RH, Petter-Puchner AH, Redl H, May C, Pospischil W, Glaser K: Assessment of pain and quality of life in Lichtenstein hernia repair using a new monofilament PTFE mesh: comparison of suture vs fibrin-sealant mesh fixation. Front Surg 2014;1:45.

39 Classification of chronic pain. Descriptions of chronic pain syndromes and definitions of pain terms. Prepared by the International Association for the Study of Pain, Subcommittee on Taxonomy. Pain Suppl 1986;3:S1S226.

40 Eklund A, Rudberg C, Leijonmarck CE, Rasmussen I, Spangen L, Wickbom G, et al: Recurrent inguinal hernia: randomized multicenter trial comparing laparoscopic and Lichtenstein repair. Surg Endosc 2007;21:634640.

41 Honigmann P, Fischer H, Kurmann A, Audigé L, Schüpfer G, Metzger J: Investigating the effect of intra-operative infiltration with local anaesthesia on the development of chronic postoperative pain after inguinal hernia repair. A randomized placebo controlled triple blinded and group sequential study design [NCT00484731]. BMC Surg 2007;7:22.

42 Nienhuijs S, Staal E, Keemers-Gels M, Rosman C, Strobbe L: Pain after open preperitoneal repair versus Lichtenstein repair: a randomized trial. World J Surg 2007;31:1751-1757; discussion 1758-1759.

43 Beldi G, Haupt N, Ipaktchi R, Wagner M, Candinas D: Postoperative hypoesthesia and pain: qualitative assessment after open and laparoscopic inguinal hernia repair. Surg Endosc 2008;22:129-133.

44 Malekpour F, Mirhashemi SH, Hajinasrolah E, Salehi N, Khoshkar A, Kolahi AA: Ilioinguinal nerve excision in open mesh repair of inguinal hernia - results of a randomized clinical trial: simple solution for a difficult problem? Am J Surg 2008;195:735-740.

45 Staal E, Nienhuijs SW, Keemers-Gels ME, Rosman C, Strobbe LJ: The impact of pain on daily activities following open mesh inguinal hernia repair. Hernia 2008;12:153-157.

46 El-Awady SE, Elkholy AA: Beneficial effect of inguinal hernioplasty on testicular perfusion and sexual function. Hernia 2009;13:251-258.

47 Sanders DL, Samarakoon DH, Ganshirt SW, Porter CS, Kingsnorth AN: A two-centre blinded randomised control study comparing the Lichtenstein patch, PerFix plug and ProLoop plug in the repair of primary inguinal hernia. Hernia 2009;13:499-503.

48 Eklund A, Montgomery A, Bergkvist L, Rudberg C; Swedish Multicentre Trial of Inguinal Hernia Repair by Laparoscopy Study Group: Chronic pain 5 years after randomized comparison of laparoscopic and Lichtenstein inguinal hernia repair. Br J Surg 2010;97:600-608.

49 Fricano S, Fiorentino E, Cipolla C, Matranga D, Bottino A, Mastrosimone A, et al: A minor modification of Lichtenstein repair of primary inguinal hernia: postoperative discomfort evaluation. Am Surg 2010;76:764-769.

50 Kapischke M, Schulze H, Caliebe A: Self-fixating mesh for the Lichtenstein procedure - a prestudy. Langenbecks Arch Surg 2010;395:317-322.

51 Myers E, Browne KM, Kavanagh DO, Hurley M: Laparoscopic (TEP) versus Lichtenstein inguinal hernia repair: a comparison of quality-of-life outcomes. World J Surg 2010;34:3059-3064.

52 Anadol AZ, Akin M, Kurukahvecioglu 0, Tezel E, Ersoy E: A prospective comparative study of the efficacy of conventional Lichtenstein versus self-adhesive mesh repair for inguinal hernia. Surg Today 2011;41:14981503.

53 Bellows CF, Shadduck PP, Helton WS, Fitzgibbons RJ: The design of an industry-sponsored randomized controlled trial to compare synthetic mesh versus biologic mesh for inguinal hernia repair. Hernia 2011;15: 325-332.

54 Sadowski B, Rodriguez J, Symmonds R, Roberts J, Song J, Rajab MH, et al: Comparison of polypropylene versus polyester mesh in the Lichtenstein hernia repair with respect to chronic pain and discomfort. Hernia 2011; 15:643-654.

55 Kim-Fuchs C, Angst E, Vorburger S, Helbling C, Candinas D, Schlumpf R: Prospective randomized trial comparing sutured with sutureless mesh fixation for Lichtenstein hernia repair: long-term results. Hernia 2012;16:21-27.

56 Koning GG, Keus F, Koeslag L, Cheung CL, Avçi M, van Laarhoven CJ, et al: Randomized clinical trial of chronic pain after the transinguinal preperitoneal technique compared with Lichtenstein's method for inguinal hernia repair. Br J Surg 2012;99:1365-1373.

57 Quyn AJ, Weatherhead KM, Daniel T: Chronic pain after open inguinal hernia surgery: suture fixation versus self-adhesive mesh repair. Langenbecks Arch Surg 2012;397:1215-1218. 
58 Singh AN, Bansal VK, Misra MC, Kumar S, Rajeshwari S, Kumar A, et al: Testicular functions, chronic groin pain, and quality of life after laparoscopic and open mesh repair of inguinal hernia: a prospective randomized controlled trial. Surg Endosc 2012;26:1304-1317.

59 Chatzimavroudis G, Papaziogas B, Koutelidakis I, Galanis I, Atmatzidis S, Christopoulos P, et al: Lichtenstein technique for inguinal hernia repair using polypropylene mesh fixed with sutures vs self-fixating polypropylene mesh: a prospective randomized comparative study. Hernia 2014;18:193-198.

60 Dhankhar DS, Sharma N, Mishra T, Kaur N, Singh S, Gupta S: Totally extraperitoneal repair under general anesthesia versus Lichtenstein repair under local anesthesia for unilateral inguinal hernia: a prospective randomized controlled trial. Surg Endosc 2014;28:996-1002.

61 Jeroukhimov I, Wiser I, Karasic E, Nesterenko V, Poluksht N, Lavy R, et al: Reduced postoperative chronic pain after tension-free inguinal hernia repair using absorbable sutures: a single-blind randomized clinical trial. J Am Coll Surg 2014;218:102-107.

62 Nienhuijs SW, Rosman C: Long-term outcome after randomizing prolene hernia system, mesh plug repair and Lichtenstein for inguinal hernia repair. Hernia 2015;19:77-81.

63 Smietański M, Bigda J, Zaborowski K, Worek M, Sledziński Z: Three-year follow-up of modified Lichtenstein inguinal hernioplasty using lightweight poliglecaprone/polypropylene mesh. Hernia 2009;13:239-242.

64 Caliskan K, Nursal TZ, Caliskan E, Parlakgumus A, Yildirim S, Noyan T: A method for the reduction of chronic pain after tension-free repair of inguinal hernia: iliohypogastric neurectomy and subcutaneous transposition of the spermatic cord. Hernia 2010;14:51-55.

65 Smietański M, Bury K, Smietańska IA, Owczuk R, Paradowski T; Polish Hernia Study Group: Five-year results of a randomised controlled multi-centre study comparing heavy-weight knitted versus low-weight, nonwoven polypropylene implants in Lichtenstein hernioplasty. Hernia 2011;15:495-501.

66 Smietański M, Smietańska IA, Modrzejewski A, Simons MP, Aufenacker TJ: Systematic review and metaanalysis on heavy and lightweight polypropylene mesh in Lichtenstein inguinal hernioplasty. Hernia 2012;16: 519-528.

67 Ruiz-Jasbon F, Norrby J, Ivarsson ML, Björck S: Inguinal hernia repair using a synthetic long-term resorbable mesh: results from a 3-year prospective safety and performance study. Hernia 2014;18:723-730.

68 van Veen RN, Wijsmuller AR, Vrijland WW, Hop WC, Lange JF, Jeekel J: Randomized clinical trial of mesh versus non-mesh primary inguinal hernia repair: long-term chronic pain at 10 years. Surgery 2007;142:695-698.

69 Jain SK, Vindal A: Gelatin-resorcin-formalin (GRF) tissue glue as a novel technique for fixing prosthetic mesh in open hernia repair. Hernia 2009;13:299-304.

70 Kucuk HF, Sikar HE, Kurt N, Uzun H, Eser M, Tutal F, et al: Lichtenstein or darn procedure in inguinal hernia repair: a prospective randomized comparative study. Hernia 2010;14:357-360.

71 Reinpold WM, Nehls J, Eggert A: Nerve management and chronic pain after open inguinal hernia repair: a prospective two phase study. Ann Surg 2011;254:163-168.

72 Pedano N, Pastor C, Arredondo J, Poveda I, Ruiz J, Montón S, et al: Open tension-free hernioplasty using a novel lightweight self-gripping mesh: medium-term experience from two institutions. Langenbecks Arch Surg 2012; 397:291-295.

73 Szopinski J, Dabrowiecki S, Pierscinski S, Jackowski M, Jaworski M, Szuflet Z: Desarda versus Lichtenstein technique for primary inguinal hernia treatment: 3-year results of a randomized clinical trial. World J Surg 2012; 36:984-992.

74 Andresen K, Burcharth J, Rosenberg J: Lichtenstein versus Onstep for inguinal hernia repair: protocol for a double-blinded randomised trial. Dan Med J 2013;60:A4729.

75 Ripetti V, La Vaccara V, Greco S, Bono F, Valeri S, Coppola R: Randomised trial comparing Lichtenstein versus Trabucco versus Valenti techniques in inguinal hernia repair. Hernia 2014;18:205-212.

76 Belyansky I, Tsirline VB, Klima DA, Walters AL, Lincourt AE, Heniford TB: Prospective, comparative study of postoperative quality of life in TEP, TAPP, and modified Lichtenstein repairs. Ann Surg 2011;254:709-714; discussion 714-715.

77 García Ureña MA, Hidalgo M, Feliu X, Velasco MÁ, Revuelta S, Gutiérrez R, et al: Multicentric observational study of pain after the use of a self-gripping lightweight mesh. Hernia 2011;15:511-515.

78 Paajanen H, Kössi J, Silvasti S, Hulmi T, Hakala T: Randomized clinical trial of tissue glue versus absorbable sutures for mesh fixation in local anaesthetic Lichtenstein hernia repair. Br J Surg 2011;98:1245-1251.

79 Kingsnorth A, Gingell-Littlejohn M, Nienhuijs S, Schüle S, Appel P, Ziprin P, et al: Randomized controlled multicenter international clinical trial of self-gripping Pariete ${ }^{\mathrm{TM}}$ ProGrip ${ }^{\mathrm{TM}}$ polyester mesh versus lightweight polypropylene mesh in open inguinal hernia repair: interim results at 3 months. Hernia 2012;16:287-294.

80 Shen YM, Sun WB, Chen J, Liu SJ, Wang MG: NBCA medical adhesive (n-butyl-2-cyanoacrylate) versus suture for patch fixation in Lichtenstein inguinal herniorrhaphy: a randomized controlled trial. Surgery 2012;151:550-555.

81 Jorgensen LN, Sommer T, Assaadzadeh S, Strand L, Dorfelt A, Hensler M; Danish Multicentre DANGRIP Study Group: Randomized clinical trial of self-gripping mesh versus sutured mesh for Lichtenstein hernia repair. Br J Surg 2013;100:474-481.

82 Paajanen H, Rönkä K, Laurema A: A single-surgeon randomized trial comparing three meshes in Lichtenstein hernia repair: 2- and 5-year outcome of recurrences and chronic pain. Int J Surg 2013;11:81-84.

83 Yilmaz A, Yener 0, Kaynak B, Yiğitbaşi R, Demir M, Burcu B, et al: Self-gripping Covidien ${ }^{\mathrm{TM}}$ ProGrip $^{\mathrm{TM}}$ mesh $^{\mathrm{s}}$ versus polypropylene mesh in open inguinal hernia repair: multicenter short term results. Prague Med Rep 2013;114:231-238. 
84 Bochicchio GV, Jain A, McGonigal K, Turner D, Ilahi O, Reese S, et al: Biologic vs synthetic inguinal hernia repair: 1-year results of a randomized double-blinded trial. J Am Coll Surg 2014;218:751-757.

85 Kurmann A, Fischer H, Dell-Kuster S, Rosenthal R, Audigé L, Schüpfer G, et al: Effect of intraoperative infiltration with local anesthesia on the development of chronic pain after inguinal hernia repair: a randomized, triple-blinded, placebo-controlled trial. Surgery 2015;157:144-154.

86 Sanders DL, Nienhuijs S, Ziprin P, Miserez M, Gingell-Littlejohn M, Smeds S: Randomized clinical trial comparing self-gripping mesh with suture fixation of lightweight polypropylene mesh in open inguinal hernia repair. $\mathrm{Br}$ J Surg 2014;101:1373-1382; discussion 1382.

87 Lauscher JC, Yafaei K, Buhr HJ, Ritz JP: Laparoscopic and open inguinal hernia repair with alloplastic material: do the subjective and objective parameters differ in the long-term course? Surg Laparosc Endosc Percutan Tech 2008;18:457-463.

88 Nikkolo C, Lepner U, Murruste M, Vaasna T, Seepter H, Tikk T: Randomised clinical trial comparing lightweight mesh with heavyweight mesh for inguinal hernioplasty. Hernia 2010;14:253-258.

89 Nikkolo C, Vaasna T, Murruste M, Seepter H, Kirsimägi Ü, Lepner U: Randomized clinical study evaluating the impact of mesh pore size on chronic pain after Lichtenstein hernioplasty. J Surg Res 2014;191:311-317.

90 Polish Hernia Study Group; Smietański M: Randomized clinical trial comparing a polypropylene with a poliglecaprone and polypropylene composite mesh for inguinal hernioplasty. Br J Surg 2008;95:1462-1468.

91 van Hanswijck de Jonge P, Lloyd A, Horsfall L, Tan R, O'Dwyer PJ: The measurement of chronic pain and healthrelated quality of life following inguinal hernia repair: a review of the literature. Hernia 2008;12:561-569.

92 Aasvang E, Kehlet H: Chronic postoperative pain: the case of inguinal herniorrhaphy. Br J Anaesth 2005;95: 69-76.

93 Alfieri S, Amid PK, Campanelli G, Izard G, Kehlet H, Wijsmuller AR, et al: International guidelines for prevention and management of post-operative chronic pain following inguinal hernia surgery. Hernia 2011;15:239-249.

94 Loney PL, Chambers LW, Bennett KJ, Roberts JG, Stratford PW: Critical appraisal of the health research literature: prevalence or incidence of a health problem. Chronic Dis Can 1998;19:170-176.

95 Breivik EK, Björnsson GA, Skovlund E: A comparison of pain rating scales by sampling from clinical trial data. Clin J Pain 2000;16:22-28.

96 Poobalan AS, Bruce J, King PM, Chambers WA, Krukowski ZH, Smith WC: Chronic pain and quality of life following open inguinal hernia repair. Br J Surg 2001;88:1122-1126.

97 Fredheim OM, Kaasa S, Fayers P, Saltnes T, Jordhøy M, Borchgrevink PC: Chronic non-malignant pain patients report as poor health-related quality of life as palliative cancer patients. Acta Anaesthesiol Scand 2008;52: 143-148.

98 Heniford BT, Walters AL, Lincourt AE, Novitsky YW, Hope WW, Kercher KW: Comparison of generic versus specific quality-of-life scales for mesh hernia repairs. J Am Coll Surg 2008;206:638-644.

99 Bay-Nielsen M, Perkins FM, Kehlet H; Danish Hernia Database: Pain and functional impairment 1 year after inguinal herniorrhaphy: a nationwide questionnaire study. Ann Surg 2001;233:1-7.

100 Cleeland CS, Ryan KM: Pain assessment: global use of the Brief Pain Inventory. Ann Acad Med Singapore 1994; 23:129-138.

101 Kehlet H, Dahl JB: Assessment of postoperative pain - need for action! Pain 2011;152:1699-1700. 